\title{
Carbon Monoxide: The Unnoticed Poison of the 21 st Century
}

\author{
J.A. Hoskins \\ Reigate, Surrey, UK
}

Carbon monoxide is the most ancient of poisons: as old as the discovery of fire itself. However, poisoning by it was probably of no great significance until the general use of coal as a domestic fuel had became widespread and consequent upon that the use of town gas made from coal or oil which was distributed to industry and to homes. A third development was, of course, the internal combustion engine. In this volume we are not concerned with carbon monoxide poisoning in the past rather we are concerned that it is still with us today. We know a lot about carbon monoxide and how dangerous it is and we should, by now, have developed strategies to avoid the danger. Unfortunately the lessons have not been learnt as several of the papers in this issue relate.

Probably the best starting point for a study of carbon monoxide poisoning today is the work of Claude Bernard, who opened a modern history of the condition in his lectures on the action of poisons [1]. Bernard devoted a lot of attention to carbon monoxide. He showed that blood saturated with the gas was no longer able to take up oxygen and he attributed its poisonous effects to this action. By preventing the combination of oxygen with haemoglobin carbon monoxide is the perfect asphyxiant. Also, since the combination with carbon monoxide is so much more stable than that made with oxygen and the reaction takes place more readily the gas in a very effective way prevents the process of respiration. In fact, the affinity of haemoglobin for carbon monoxide is some 240 times that for oxygen [2]. A simple chemical reaction that takes place as readily in the body as it does in the testtube. Experiments suggest that this formation of carboxyhaemoglobin is the main, possibly the only, important, biochemical event of carbon monoxide poisoning. Insects without haemoglobin, such as cockroaches, have survived for weeks breathing an atmosphere of $80 \%$ carbon monoxide and $20 \%$ oxygen. To them the gas is as inert as nitrogen. Even an animal as large as a mouse can survive with its blood fully saturated with carbon monoxide if it is breathing hyperbaric oxygen because, through simple solution, sufficient oxygen for life dissolves in the blood. Larger animals would not be so lucky.

The use of oxygen in the treatment of carbon monoxide asphyxia is not modern medicine. It can be traced back to the work of Claude Bernard noted above and when reading it we should remember that oxygen had only been discovered less than 100 years before in 1772 by Scheele. Bernard did not have the advantage of purified gas conveniently delivered in a metal cylinder. He had to prepare the element and store it in a bladder or a gas jar. Not an easy task. Since then, and with oxygen more readily available, experience both in the laboratory and in the field has amply demonstrated the beneficial effect of inhaling oxygen in both mild and severe carbon monoxide poisoning. It is long proven that recovery from dangerous asphyxia as well as alleviation of the headaches and other symptoms of less severe poisoning is substantially promoted when oxygen is given. If an individual is poisoned by carbon monoxide then to maintain life the remaining available haemoglobin in their blood will have to be saturated with oxygen when the blood passes through the lungs. To ensure complete saturation it is necessary to increase the concentration of oxygen breathed from the

\section{KARGER \\ Fax + 41613061234 \\ E-Mail karger@karger.ch} www. karger.com
두 1999 S. Karger AG, Basel

Accessible online at: www. karger.com/journals/ibe 
$20 \%$ available in air to around $93 \%$ (the difference is made up with carbon dioxide which among a number of things stimulates more active breathing and facilitates release of oxygen to the tissues). If the poisoning is severe then even ' $100 \%$ oxygen' is not enough. The partial pressure of oxygen has to be increased still more and the only way to do this is to increase the pressure of the gas breathed, to treat the patient with hyperbaric oxygen. It is on this juggling with partial pressures and a good understanding of respiratory physiology that the treatment for carbon monoxide poisoning relies.

Over 100 years ago the great J.B.S. Haldane [3] in 1895 studied the clinical development of acute carbon monoxide poisoning up to the point of unconsciousness in experiments such as that conducted upon himself. Haldane inhaled air containing $0.21 \%$ carbon monoxide for 71.5 min. At the end of this time his blood was $49 \%$ saturated with carbon monoxide and he was seriously affected being probably on the verge of unconsciousness. With little doubt another half-hour of inhalation would have resulted in death at around $70 \%$ saturation. He described his symptoms as the poisoning progressed and after inhalation of the gas had stopped. Fortunately he survived the experience with nothing worse than a headache the following day. Today, we know that he was lucky to do so. From such experiments it has been found that in naïve subjects $20 \%$ saturation is the critical point at which subjective effects are experienced.

Carbon monoxide is not a cumulative poison in the absence of exposure. The distinction must be drawn between the effects of chronic exposure and the sequelae of severe acute exposure. There are toxins, such as lead and crystalline silica, and uncommon ones such as radium, which can build up and be stored in the body in increasing amounts as exposure is continued. In this way toxic material is stored up which may continue to damage the body long after its owner has removed themself from the source. It is clear there is no possibility (apart from its combination with haemoglobin) by which carbon monoxide can accumulate in the body. For it to produce chronic effects chronic exposure is essential. Consider a possible scenario. A garage worker who had daily exposure for several months, exposure severe enough to cause headaches and nausea every workday afternoon. He will no longer suffer from these effects if the ventilation of the garage is made adequate or he changes his job to one where there is no carbon monoxide in the air. If though, through his exposure, he developed either anaemia or polycythaemia (an increase in the number of red cells) then either of these conditions may persist for several months but they ex- press harm done when the man was actually in the gas, not harm done by retaining the gas after exposure to it ceased. The same issue not infrequently arises in connection with the neurological sequelae that may follow profound poisoning. Sometimes neurological changes do not show themselves immediately but are delayed for a period of maybe several weeks. The hypoxic stress which caused these changes occurred at the time of the poisoning and they are not a consequence of the gas being stored in the body.

It is of interest that one may become acclimatised to low levels of carbon monoxide. This may be pertinent to people who are regularly exposed to levels of carbon monoxide considered too low to be of any significance. Exposure continued over a period of weeks may result in an individual becoming, to a degree, resistant to the effects of the gas. Again, Haldane [3, 4] is the source of the observation. With a co-worker he was conducting experiments in which, for reasons having nothing to do with carbon monoxide poisoning, they were breathing, nearly every day, air containing a small amount of carbon monoxide. As their experiments continued they found that in order to produce a $30 \%$ saturation of the haemoglobin in their blood - the degree of saturation that would result in definite symptoms - they had to inhale about $0.06 \%$ of carbon monoxide (six parts in 10,000). After this experiment an interval elapsed during which they no longer were exposed to $\mathrm{CO}$. They then found that they needed to inhale carbon monoxide only at $0.04 \%$ for $30 \%$ saturation to occur. It was evident that during the first period of exposure the investigators had become acclimatised to carbon monoxide without knowing it. After a period of readjustment less carbon monoxide was required to produce symptoms of poisoning. It is not difficult to imagine circumstances in which this resistance would have a serious effect. Workers for example returning after a period away from their workplace due to holiday or illness could suffer ill-effects from a work environment to which in the past they had been immune. It should not happen but it probably does.

\footnotetext{
References

1 Bernard C: Leçons sur les effets des substances toxiques et médicamenteuses. Paris, Baillière et Fils, 1857.

2 Carbon monoxide: Environmental Health Criteria 13. Geneva, WHO, 1979.

3 Haldane JBS: The action of carbonic oxide upon man. J Physiol 1895;18:201.

4 Haldane JBS, Smith JL: The oxygen tension of arterial blood. J Physiol 1896;20:497.
} 